NOAA

National Marine

Fisheries Service
Fishery Bulletin

¿ established 1881 ๙
Spencer F. Baird

First U.S. Commissione of Fisheries and founder of Fishery Bulletin
Abstract-Analysis of the life history of the thumbprint emperor ( $L e$ thrinus harak) sampled from Saipan Lagoon during 2005-2006 revealed sex-specific differences in von Bertalanffy age and growth parameters. Length at $50 \%$ reproductive maturity was estimated as $19.6 \mathrm{~cm}$ fork length (FL) for females and as 18.7 cm FL for males for the corresponding ages of 2.6 and 2.4 years. Available data from several sources for this data-poor coral reef fish were analyzed to assess its population status in Saipan Lagoon, Northern Marianna islands. Estimates of total mortality $(Z)$ within the period 2005-2011 were derived by using length-converted catch-curve analysis and the Chapman-Robson estimator. Natural mortality $(M)$ was estimated from 3 models based on applicable observations and parameter estimates derived from data for thumbprint emperor in Saipan Lagoon. Exploitation ratios $(E)$ derived with combinations of $Z$ and $M$ estimators within the period 2005-2011 showed a wide disparity, although no estimate of average annual $E$ exceeded 0.5 (an $E$ over that threshold would have indicated overexploitation). Location-specific life history studies should be pursued to support local research and management goals. Standardized methods for the estimation of life history parameters would allow empirical comparisons between regions.

Manuscript submitted 31 December 2015. Manuscript accepted 28 June 2016.

Fish. Bull. 114:409-425 (2016).

Online publication date: 8 August 2016 . doi: 10.7755/FB.114.4.4

The views and opinions expressed or implied in this article are those of the author (or authors) and do not necessarily reflect the position of the National Marine Fisheries Service, NOAA.

\title{
Life history characteristics and stock status of the thumbprint emperor (Lethrinus harak) in Saipan Lagoon
}

\author{
Michael S. Trianni \\ Email address for contact author: michael.trianni@noaa.gov \\ Pacific Islands Fisheries Science Center \\ National Marine Fisheries Service, NOAA \\ P.O. Box 8216 \\ Saipan, Northern Mariana Islands 96950
}

Coral reef fishes of the family Lethrinidae, the emperors, are widely distributed throughout the tropical and subtropical Indo-Pacific, where they are primary targets of important commercial and noncommercial fisheries (Carpenter, 2001). Annual global landings of emperors rose sharply beginning in the mid-1970s and started to level off at about 84,000 metric tons ( $\mathrm{t}$ ) in the mid-1990s, according to statistics accessed through the Food and Agriculture Organization of the United Nations, FAO application FishStatJ, vers. 2.2.0 (Capture Production data set, available at website). As a result of the increase in landings, numerous studies have been directed at estimating life history characteristics for lethrinid species that are targeted in commercial and noncommercial fisheries (Brown and Sumpton, 1998; Laursen et al., 1999; Grandcourt, 2002; Kulmiye et al., 2002; Sumpton and Brown, 2004; Ebisawa, 2006; Williams et al., 2007; Ebisawa and Ozawa, 2009; Trianni, 2011; Currey et al., 2013), and additional studies have focused on other topics, including demographics (spatial and temporal), status designations, or both (Dalzell et al., 1992; Williams et al., 2003; Williams et al., 2007; Grandcourt et al., 2010; Taylor and McIlwain, 2010).

For most coral reef fishes caught in the central and western Pacific under
U.S. jurisdiction, landings data are inconsistent or unreliable and there is a lack of estimates for jurisdiction-specific life history parameters $\left(\mathrm{WPRFM}^{1}\right)$. As a result, these data often are insufficient to support formal stock assessments. The issue of datapoor fishery resources has in recent years led to an array of techniques designed to address data shortfalls. Examples of such approaches were specific natural mortality estimates, extended time-series of landings, or both (MacCall, 2009; Dick and MacCall, 2011); stock assessments with hierarchical Bayesian models that allow data for poor-data species to be borrowed from data for similar species for which "good-quality data" exist in single (Jiao et al., 2011) or multispecies fisheries (Punt et al., 2011); and density ratios that reflect both larval dispersal and adult movement patterns for species that occur within and outside of functional marine protect areas (McGilliard et al., 2011). The data required for these methods tend to differ from or exceed existing information for coral reef fisheries in U.S. jurisdictions in

${ }^{1}$ WPRFMC (Western Pacific Regional Fishery Management Council). 2009. Fishery ecosystem Plan for the Mariana Archipelago, 231 p. Western Pacific Regional Fishery Management Council, Honolulu. [Available at website] 


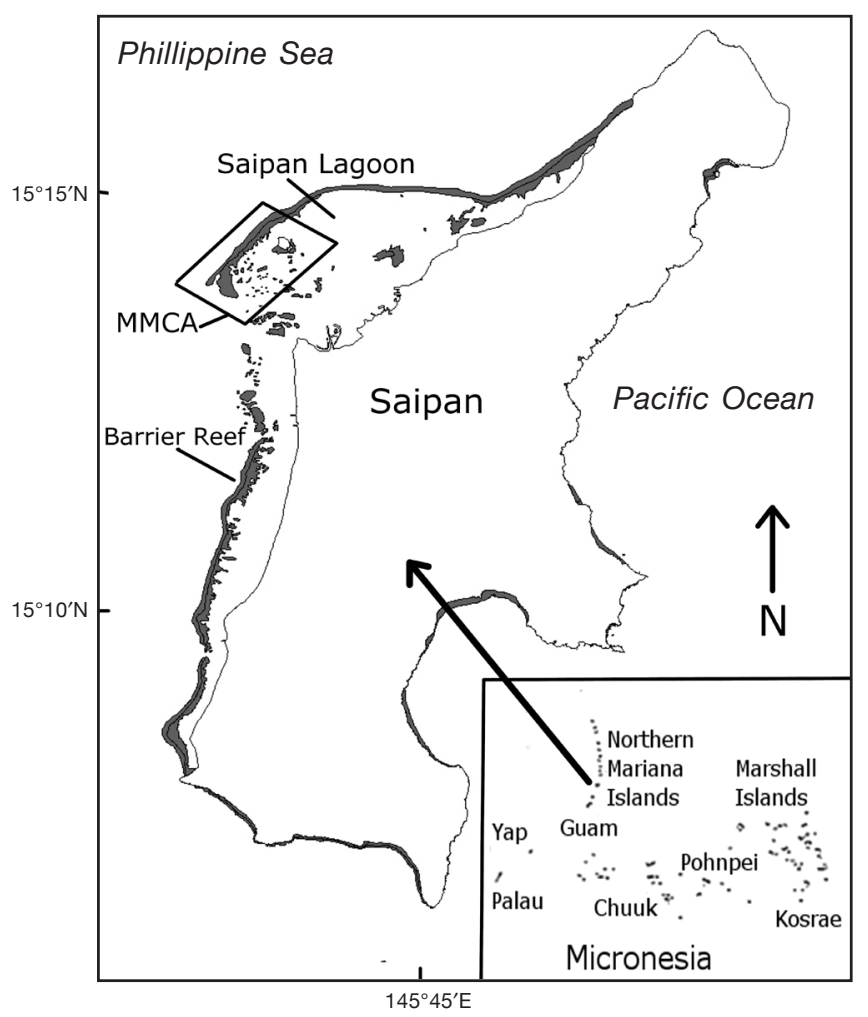

Figure 1

Map of the island of Saipan in the Mariana Archipelago showing the spatial extent of Saipan Lagoon and the boundaries of the Mãnagaha Marine Conservation Area (MMCA).

the central and western Pacific; therefore, the application of these techniques for U.S. Pacific Island fisheries is limited. Species-specific evaluation in U.S jurisdictions will need to occur on a case-by-case basis and incorporate appropriate levels of analysis.

A protogynous hermaphrodite, the thumbprint emperor (Lethrinus harak), ranges throughout the IndoPacific region, including the Red Sea, where it is found in various habitats, including mangroves, lagoon seagrass habitats (Carpenter, 2001; Shibuno et al., 2008; Nakamura et al., 2009), expanded reef flats (Taylor and McIlwain, 2010), and sand environments on protected outer reef slopes (Myers, 1999). This species occurs solitarily or in groups of a few individuals and exhibits high diurnal site fidelity (Nanami and Yamada, 2009). Its diet consists of benthic invertebrates and small fishes (Carpenter, 2001). The thumbprint emperor can be a dominant species in landings from nearshore fisheries for which the primary methods of capture include gill nets, surround nets, and hook and line (Dalzell et al., 1996; Carpenter, 2001; Ebisawa, 2006; Taylor and McIlwain, 2010).

At Saipan in the Commonwealth of the Northern Mariana Islands (CNMI), the thumbprint emperor is a numerically dominant reef fish species in Saipan Lagoon. Historically, this fish was primarily harvested with gill and surround nets and, to a lesser extent, with hook and line and by free-dive spearfishing. Since December 2003, the use of gill nets, drag nets (which are gill nets dragged along the bottom in a manner similar to that used with beach seines), and surround nets in the CNMI have been restricted by the CNMI Department of Lands and Natural Resources (DLNR), and their use is allowed only for annual cultural fiestas through a special exemption granted by the DLNR. Hook and line has become the primary harvest method, followed by free-dive spearfishing. Given the importance of the thumbprint emperor as a major component of the coral reef fish community in Saipan Lagoon and the lack of biological data for this species, the DLNR Division of Fish and Wildlife (DFW) conducted research from 2005 through 2006 during which period age and growth and reproductive data were collected. This data collection effort corresponded with the commencement of a DFW creel survey program in 2005 that was designed to reflect fishing activity in Saipan Lagoon.

The objective of the present study was to use the thumbprint emperor as an example species in an examination of the challenges in assessing data-poor fisheries. This work drew on available data pertinent to the thumbprint emperor from Saipan Lagoon and this article presents estimates of life history parameters and mortality rates from 2 models for total mortality $(Z)$ and 3 models for natural mortality $(M)$. Generated rates of exploitation of the thumbprint emperor are provided here, along with biological and fishery metrics, to examine the status of this species in Saipan Lagoon.

\section{Materials and methods}

\section{Study site}

Saipan Lagoon extends along the western side of the island of Saipan and is bordered by a nearly continuous barrier reef (Fig. 1). The habitat that covers the largest amount of area in Saipan Lagoon is composed of unconsolidated sands, followed, in descending size, by a deeper ( $>7 \mathrm{~m}$ average depth) sandy area interspersed with consolidated coral reef structure (deep patch-reef), seagrass beds (Halodule spp. and Enhalus spp.), midlagoon zones of coral rubble, and backreef. Depths in Saipan Lagoon range from $<1 \mathrm{~m}$ in nearshore areas to about $15 \mathrm{~m}$ in the main shipping channel. The lagoon serves as the primary area for a variety of recreational activities that do not involve the extraction of resources, as well as the primary grounds for noncommercial and commercial fishing for the island of Saipan. The principal fishing gears include hook and line, free-dive fishing with a spear gun, and cast net or talaya. Spearfishing with scuba gear is prohibited throughout the CNMI by public law (CNMI Admin. Code $\S 85-30.1-401)$. The restrictions on net use issued by DLNR allow a total annual catch of reef fish of about $907 \mathrm{~kg}$ (2000 lb). The no-take Mañagaha Marine Con- 


\section{Table 1}

Macroscopic sex-specific gonad criteria used to assign maturity class to thumbprint emperor (Lethrinus harak) collected from Saipan Lagoon during 2005-2006.

\begin{tabular}{|c|c|c|c|}
\hline Stage & Male & Female & Maturity class \\
\hline 1 Immature & $\begin{array}{l}\text { Gonads long and slender, threadlike, and } \\
\text { translucent. }\end{array}$ & $\begin{array}{l}\text { Gonads long and slender, transparent or } \\
\text { pinkish in color. Oocytes not discernible. }\end{array}$ & Inactive \\
\hline 2 Developing & $\begin{array}{l}\text { Grayish-white in color, beginning to } \\
\text { swell in girth. }\end{array}$ & $\begin{array}{l}\text { Ovaries elongated, some beginning to } \\
\text { swell in girth. Individual oocytes not } \\
\text { discernible. Some blood vessels apparent. } \\
\text { Color pink to light pink. }\end{array}$ & Active \\
\hline 3 Mature or ripe & $\begin{array}{l}\text { Thickened, white to beige in color, } \\
\text { blood vessels visible, milt exudes when } \\
\text { gonad is squeezed. For gonads with fur- } \\
\text { ther thickening, milt exudes on slight } \\
\text { pressure. }\end{array}$ & $\begin{array}{l}\text { Ovaries long and swollen with large } \\
\text { oocytes visible through thin ovary wall. } \\
\text { Blood vessels easily visible or disappear- } \\
\text { ing. Color dark pink to red. Ova easily } \\
\text { exuded upon application of pressure. } \\
\text { Blood vessels disappearing. Color yellow } \\
\text { to orange. }\end{array}$ & Active \\
\hline 4 Spent & $\begin{array}{l}\text { Flaccid in appearance, thickened gonad } \\
\text { wall loose and furrowed. Little to no milt } \\
\text { exudes upon application of pressure. }\end{array}$ & $\begin{array}{l}\text { Ovaries flaccid, partially empty in ap- } \\
\text { pearance, and color faded from dark yel- } \\
\text { low to brown. Ovary wall thick. }\end{array}$ & Active \\
\hline
\end{tabular}

servation Area (MMCA) surrounds Mañagaha Island, a cay within Saipan Lagoon, and includes fringing reef, coral and rubble, deep patch-reef, and sand-dominated habitats.

\section{Data sources: fishery independent}

Sampling During 2005-2006, staff working in the DFW life history program obtained monthly samples of thumbprint emperor, using hook and line, to develop estimates of reproduction, age, and growth. Specimens were measured to the nearest $1 \mathrm{~cm}$ in fork length (FL) and weighed to the nearest $0.1 \mathrm{~g}$. Sex of fish was determined and fish were assigned to a status of either immature or sexually active (mature) on the basis of macroscopic examination (Table 1). Excised whole gonads were weighed to the nearest $0.01 \mathrm{~g}$ with an electronic scale. To process them for reading, sagittal otoliths were embedded in epoxy resin, cut transversely into 300-500 $\mathrm{\mu m}$ sections through the otolith core by using a low-speed saw, and were smoothed with abrasive paper of 600-1200 grit until the annuli were visible. These sections were then mounted on a glass slide with thermoplastic cement and hand polished with 0.3um alumina powder (Choat et al., 1996).

With the use of a dissecting microscope with transmitted light, each sectioned and mounted otolith was read randomly 3 times for counts of annual increments between the core and outer otolith edge.

The final age was decided when 2 of the readings agreed (Choat and Axe, 1996). The margins of otoliths were assessed and assigned to one of the 3 classifications based on the relative stage of marginal increment formation. Margins were classified as thin if opaque material was visible but not necessarily continuous around the otolith margin; medium wide if there was a continuous increment of translucent material that was less than two-thirds complete (based on the width of the prior translucent increment) and visible on the outermost margin of the opaque increment; and wide if the marginal translucent increment was more than two-thirds complete. A classification of thin was indicative of a new annual mark and counted as a year. Otolith processing, age determination, and marginal edge analysis were conducted by the fish aging laboratory at James Cook University, Townsville, Australia.

Biomass surveys The DFW conducted underwater visual census (UVC) surveys in 2004, 2007, and 2011 in the southern portion of Saipan Lagoon to measure the influence of restrictions on net use imposed in December 2003. In these surveys, 4 major lagoon habitat units were surveyed on the basis of dominant substrate by using belt transects of $25 \times 5 \mathrm{~m}$ (counts of 10-15 min) for fish $<20 \mathrm{~cm} \mathrm{FL}$ and by using stationary point counts with a $10-\mathrm{m}$ radius (8-min duration) for fish $\geq 20 \mathrm{~cm}$ FL. For these surveys, standard DFW fishery-independent UVC techniques were used and the surveys were conducted by using a proportional allocation design (Cochran, 1977). Additionally, the same UVC survey techniques were used to estimate biomass of thumbprint emperor for the deep patch-reef habitat in the MMCA. Results from these surveys were used to obtain estimates of total biomass of thumbprint emperor from Saipan Lagoon for 2007 and 2011 by using the following equations (Cochran, 1977): 


$$
\begin{gathered}
\bar{X}_{\mathrm{H}}=\sum_{h}^{H} \bar{x}_{\mathrm{h}} \times \frac{h}{H} \text { and } \\
Y=\bar{X}_{\mathrm{H}} \times H,
\end{gathered}
$$

where $\bar{X}_{\mathrm{H}}=$ overall habitat mean $\left(\mathrm{g} / \mathrm{m}^{2}\right)$;

$\bar{x}_{\mathrm{h}}=$ habitat unit mean $\left(\mathrm{g} / \mathrm{m}^{2}\right)$;

$H=$ total size all habitats $\left(\mathrm{m}^{2}\right)$;

$h=$ habitat unit size $\left(\mathrm{m}^{2}\right)$; and

$Y=$ estimated total $(\mathrm{g})$.

Biomass estimates of thumbprint emperor were not available from 2007 because most individuals of Lethrinus were recorded only at the genus level. As a result, although there is uncertainty in the amount of error associated with this approach, the biomass of species of Lethrinus estimated for 2007 was multiplied by the proportion of species of Lethrinus identified as thumbprint emperor in surveys in which UVC methods were used during 2011.

\section{Data sources: fishery dependent}

Inshore creel survey The DFW currently operates an inshore creel survey (ICS) that targets Saipan Lagoon. The ICS collects data on nonvessel fishing activities that involve gear that includes hook and line, free-dive with a spear gun (pachinko and cast net [talaya]). For this study, length-frequency data and estimated annual landings of the thumbprint emperor for the years 2005-2011 were obtained from the ICS database.

Exemptions from net-use restrictions In December 2003, the DLNR established regulations that prohibit the use of gill, drag, and surround nets, except as exempted by the DLNR for special cultural events, such as annual fiestas. Catch quotas of 68-136 kg (from 150 to $300 \mathrm{lb})$ with a 2-to-3-day time limit were established for exemptions (net-use exemptions, NUE, under an annual limit of $907 \mathrm{~kg}$ [2000 lb.]) For all fishing activities exempted from DLNR regulations through 2011, surround nets (chenchulun umesugon) were used and the landings taken under these exemptions were monitored by the DFW. In this study, landings taken under the NUE were used in estimating total annual landings and recording length-frequency measurements for thumbprint emperor.

Tracking commercial landings In the CNMI, the primary means of tracking commercial landings of coral reef fishes is the DFW Commercial Purchase Database System (CPDS), a database that tracks commercial purchases and sales recorded on trip tickets provided by DFW and voluntarily submitted by vendors. Additionally, in 2011, a biosampling program (BSP) for coral reef fish commenced in the CNMI. Several times a week, the BSP sampled reef fish for species identification, length frequency in centimeters in FL, and body weight in grams from randomly selected catches of fishermen before commercial sale. The BSP also collected daily data on vendor purchases from fishermen, in an effort similar to that of the CPDS. In 2011, the BSP sampled $19 \%$ of total reef fish landings from the coral reef spear fishery. The proportion of thumbprint emperor among the total biomass of coral reef fishes recorded during the BSP sampling in 2011 was used to estimate total landings of thumbprint emperor by multiplying the proportion of thumbprint emperor by the estimated CPDS annual landings of lethrinids during 2006-2011.

\section{Data analyses}

Size at maturity Data from the macroscopic determination of sex and reproductive status were partitioned into 1-cm-FL classes for the analysis of female length at $50 \%$ maturity $\left(L_{50}\right)$, female age at $50 \%$ maturity $\left(A_{50}\right)$, and length $\left(L_{\mathrm{T}}\right)$ and age $\left(A_{\mathrm{T}}\right)$ at $50 \%$ sex transition from female to male. A logistic model was used for these estimations:

$$
P=1 /\left(1+e^{\left(a-b X_{f}\right)}\right)
$$

where $a$ and $b=$ the fitted model constants;

$P=$ the percent mature or transitioned in length or age class,

$X_{\mathrm{f}}=$ length or age class; and

$L_{50}$ or $A_{50}=-\frac{a}{b}$.

This model was weighted by the square root of the numbers of fish in each length class, and the regression parameters were estimated by using maximum likelihood with a binomial logistic link function. Biascorrected percentile confidence intervals were produced around all estimates from 1000 resamples drawn with replacement ( $\mathrm{R}$ Core Team, 2015).

Age and growth A nonlinear least squares model was used to fit the standard von Bertalanffy growth function (VBGF) (von Bertalanffy, 1938) to length-at-age data. The VBGF is defined with the following equation:

$$
L_{t}=L_{\infty}\left(1-e^{-k\left(t-t_{0}\right)}\right),
$$

where $L_{\mathrm{t}}=$ the length at time $t$;

$L_{\infty}=$ the asymptotic length;

$\stackrel{\infty}{k}=$ the Brody growth coefficient; and

$t_{0}=$ the theoretical age at which length is equal to 0 .

Data were fitted both by not constraining $t_{0}$ and by constraining it to an estimated age at settlement from Japan (Nakamura, et al. 2010). Growth curves generated from the VBGF fitting procedure were subsequently tested for equality by using the analysis of residual sum of squares (ARSS) method developed by Chen et al. (1992) for male and female comparisons. Parameters of the length-weight relationship were obtained by fitting the following power function

$$
W=a \times F L^{\mathrm{b}}
$$

to length and weight data, 
where $W=$ the total wet weight; and

$a$ and $b=$ the associated equation constants (R Core Team, 2015).

Total mortality The expectation-maximization algorithm approach developed by Hoenig and Heisey (1987) was used to create length-age keys from the 2005 and 2006 life history data, and those keys were used to estimate age groups from length-frequency data collected in subsequent years from the ICS and NUE data. The annual instantaneous rate of $Z$ was subsequently determined with the age-based catch-curve (CC) method (Beverton and Holt, 1957) in its linearized form:

$$
\ln \left(C_{\mathrm{t}}\right)=\ln \left(N_{0}\right)-Z t
$$

where $C_{\mathrm{t}}=$ the catch in year $t$;

$N_{0}=$ recruitment into cohort; and

$Z t=$ the instantaneous rate of $Z$ at age $t$.

The descending limb of the plot of the natural logarithm of relative abundance versus age (time) was used to estimate $Z$ with exclusion of derived age groups beyond the first age class where one or fewer individuals were observed (Dunn et al., 2002). Additionally, $Z$ was estimated by using the maximum likelihood estimator for catch curves developed by Chapman and Robson (Chapman and Robson, 1960; Robson and Chapman, 1961):

$$
Z=-\log \left(\frac{T}{n+T-1}\right),
$$

where $n=$ the total number of fish observed on the descending limb of the catch curve, defined as fully recruited; and

$T=$ the fish ages on the descending limb of the catch curve, where the first fully recruited age is set to 0 .

Estimates of $Z$ from the use of both methods, and both age-length keys, were generated yearly as permitted by the availability of data from the ICS, as well as the availability of the NUE data.

Natural mortality Three models were used to estimate the instantaneous rate of $M$. For one model, the predictive equation developed by Hoenig (1983) was used; the equation relates the maximum age observed in a stock to $M$ :

$$
\ln (M)=1.46 \times 1.01 \times \ln \left(t_{\max }\right),
$$

where $t_{\max }=$ the maximum age observed in the population.

Another model was Lorenzen's (1996) power function of weight for natural populations:

$$
M=3 W^{-0.288},
$$

where $W$ is weight $(\mathrm{g})$.

Finally, the third model was the mortality estimator based on the empirical equation by Gislason et al. (2010):

$$
\log M=0.55-1.61 \log L+1.44 L_{\infty} \log k,
$$

where $L=$ the fish fork length;

$L_{\infty}=$ the asymptotic length; and

$\stackrel{\infty}{k}=$ the instantaneous growth coefficient.

Spawning potential ratios Goodyear (1993) summarized the concept of spawning potential ratio (SPR) and evaluated it against other traditional fisheries reference points, defining SPR as a ratio of the potential recruit fecundity $(P)$ in an exploited stock to the potential recruit fecundity in an unexploited stock:

$$
S P R=\frac{P_{\text {fished }}}{P_{\text {unfished }}},
$$

where $P=\sum_{i=j}^{n}\left(E_{i} * F r_{i}\right) * \exp ^{\left(-\left(\mathrm{F}_{\mathrm{i}}+\mathrm{M}_{\mathrm{i}}\right)\right.}$,

$n=$ the number of female length classes;

$E=$ the mean fecundity of females at length $i$;

$F r_{\mathrm{i}}=$ the fraction of females at length $i$ that were mature;

$F i=$ the fishing mortality rate of females at age $i$; and

$M=$ the natural mortality rate of females at age $i$.

The SPR was estimated by calculation of $P$ in the absence of fishing mortality $(F=0)$ and with various levels of fishing mortality $(F>0)$. Length classes included the smallest mature female and the largest measured female observed during sampling by the DFW during 2005-2006.

Mean fecundity per size class for thumbprint emperor was estimated by using the fecundity relationship (batch fecundity $=1.58 \times 0^{-3} \times \mathrm{FL}^{5.2}$ ) provided by Ebisawa (1990) for the spangled emperor (Lethrinus nebulosus), a phylogenetically related species (Lo Galbo et al., 2002) with similar trophic-level characteristics (Carpenter, 2001). The fraction of females that were mature for a specific FL was estimated from collected length-at-maturity data. The fishing mortality rate was multiplied by a selection coefficient that was assumed to increase linearly with length from 0.0 at 1 $\mathrm{cm}$ less than the smallest length sampled to 1.0 at 1 $\mathrm{cm}$ greater than the modal length in the length distribution. Through the use of growth parameter estimates derived from the VBGF, $M$ was estimated from the empirical equation of Gislason et al. (2010) and applied as estimated for each length class. The ratio of estimated total annual landings of thumbprint emperor from fishery-dependent data sources over estimated biomass from the fishery-independent surveys conducted in 2007 and 2011 approximated estimates of fishing mortality (Beddington and Kirkwood, 2005), and those estimates of fishing mortality were then used to assess SPR for the period 2005-2011.

Exploitation The exploitation ratio $(E)$ was computed as $E=F / Z$, where $Z=M+F$ (Gulland, 1971) and $F$ is instantaneous fishing mortality. An $E$ value at or near 0.5 is considered indicative of full exploitation, al- 


\section{Table 2}

Number of male and female fish sampled, percentage of fish that were male, and sex ratio by length bin for thumbprint emperor (Lethrinus harak) collected during 2005-2006 from Saipan Lagoon. $n=$ sample size.

\begin{tabular}{lrrccc}
\hline $\begin{array}{l}\text { Fork length }(\mathrm{cm}) \\
\text { ratio(M:F) }\end{array}$ & $n$ & Male & Female & Male (\%) & Sex \\
\hline $10.0-11.9$ & 6 & 3 & 3 & 0.50 & $1.0: 1.0$ \\
$12.0-13.9$ & 9 & 1 & 8 & 0.11 & $1.0: 8.0$ \\
$14.0-15.9$ & 37 & 8 & 29 & 0.22 & $1.0: 3.6$ \\
$16.0-17.9$ & 88 & 19 & 69 & 0.22 & $1.0: 3.6$ \\
$18.0-19.9$ & 109 & 19 & 90 & 0.17 & $1.0: 4.7$ \\
$20.0-21.9$ & 98 & 16 & 82 & 0.16 & $1.0: 5.1$ \\
$22.0-23.9$ & 116 & 38 & 78 & 0.33 & $1.0: 2.1$ \\
$24.0-25.9$ & 80 & 36 & 44 & 0.45 & $1.0: 1.2$ \\
$26.0-27.9$ & 18 & 5 & 13 & 0.28 & $1.0: 2.6$ \\
$28.0-29.9$ & 5 & 0 & 5 & 0.00 & - \\
$30.0-31.9$ & 2 & 1 & 1 & 0.50 & $1.0: 1.0$ \\
$32.0-33.9$ & 2 & 1 & 1 & 0.50 & $1.0: 1.0$ \\
& & & & &
\end{tabular}

though Pauly (1984) suggested a more conservative value of 0.2 for lower-trophic-level, small-size fish with high recruitment variability. Although the thumbprint emperor is a higher-trophic-level species, the value of 0.2 could serve as a lower bound for $E$ for this species. To obtain uncertainties around estimates of $E$, in this study, uncertainties around $Z$ and $M$ were first obtained by sampling with replacement (1000 resamples). For $Z$, obtaining uncertainties was accomplished by resampling within the ranges of the estimated annual values from both the CC and the Chapman-Robson (CR) methods. Estimates of $M$ uncertainty were derived by resampling within boundaries of applicable model parameters: within the uncertainties (confidence intervals) of estimated VBGF age and growth parameters for thumbprint emperor from this study with the Gislason model; within the range of weights (Lorenzen model) or lengths (Gislason model) observed from sampling thumbprint emperor from this study; within the maximum ages (Hoenig equation) of thumbprint emperor estimated from this study and from Taylor and McIlwain (2010) for Guam.

Estimates of $F$ were subsequently derived by resampling (1000 resamples) the equivalency $Z=M+F$, rearranged as $F=Z-M$, by using results from the resampled $M$ and $Z$ estimators. All analyses were conducted with $\mathrm{R}$ statistical software ( $\mathrm{R}$ Core Team, 2015).

\section{Results}

\section{Reproduction}

The overall observed male-to-female sex ratio for the thumbprint emperor from the CNMI for the period 2005-2006 was 1.0:2.9, and females were predominant in most size classes (Table 2). The estimated $L_{50}$ and
$A_{50}$ for females were $19.6 \mathrm{~cm} \mathrm{FL}$ and 2.6 years, respectively (Table 3 ). Values of the gonadosomatic index for female thumbprint emperor began to increase concomitant with a decrease in the percentage of immature individuals at size, elevating noticeably at around 19-20 cm FL (Fig. 2), with fewer samples from size classes greater than $27 \mathrm{~cm} \mathrm{FL}$ (Table 2). Estimates of age and length at the transition from females to males were not obtained because the expected change in sex ratio-a change to more males and fewer females that would indicate sex transition-was not observed (Table 2).

\section{Age and growth}

Results from the marginal edge analysis completed in 2005 and 2006 indicated that otolith accretion with a margin classification of new (opaque material visible on otolith margin), occurred from June through October (Fig. 3, A and B). The oldest individuals collected were an age- 9 male at $27.6 \mathrm{~cm}$ FL and an age-9 female at $29.3 \mathrm{~cm}$ FL. The estimates of unconstrained overall, sex-specific, and constrained VBGF parameters are provided in Table 4. Growth curves for the combined unconstrained, sex-specific, and constrained model fits are displayed in Figure 4. Estimates of $L_{\infty}$ and $k$ for male and female thumbprint emperor from Saipan differed substantially; females were estimated to have a larger $L_{\infty}$ and lower $k$. The ARSS model used to analyze the sex-specific growth curves revealed significant differences between the sexes $(P=0.016)$ and years $(P=0.004)$.

\section{Length frequency, biomass, and landings}

Percent contributions of measured thumbprint emperor per length class generated from ICS and NUE data were graphically compared with data from female and male size histograms developed from DFW sampling in 
Table 3

Reproductive life history parameters for thumbprint emperor (Lethrinus harak) as estimated from locations in the Indo-Pacific: female size at $50 \%$ maturity $\left(L_{50}\right)$ with confidence intervals (CIs), female age at $50 \%$ maturity $\left(A_{50}\right)$ with CIs, length at transition from female to male $\left(L_{\mathrm{T}}\right)$, age at transition from female to male $\left(A_{\mathrm{T}}\right)$, and sex ratio $(\mathrm{M}: \mathrm{F})$. The number of male and female thumbprint emperor sampled appear in parenthesis below each location. All lengths are fork lengths measured to the nearest centimeter.

\begin{tabular}{lccccc}
\hline Location & Female $L_{50}(\mathrm{CI})$ & Female $A_{50}(\mathrm{CI})$ & $L_{\mathrm{T}}$ & $A_{\mathrm{T}}$ & $\mathrm{M}: \mathrm{F}$ \\
\hline $\begin{array}{l}\text { Saipan } \\
(150,420)\end{array}$ & $19.6(19.1-19.9)$ & $2.6(2.4-2.8)$ & - & - & $1.0: 2.9$ \\
$\begin{array}{c}\text { Guam } \\
\quad(85,328)\end{array}$ & 20.8 & 3.8 & 24.1 & 5.38 & $1.0: 3.8$ \\
$\begin{array}{c}\text { Ryukyu Islands } \\
(194,254)\end{array}$ & $19.5^{2}$ & $1.0-2.0^{3}$ & $25.5^{2}$ & - & $1.0: 1.3^{2}$ \\
$\begin{array}{c}\text { Kenya }^{4} \\
(386,426)\end{array}$ & 24.3 & - & - & - & $1.0: 1.1$ \\
\hline
\end{tabular}

${ }^{1}$ Taylor and McIlwain, 2010.

${ }^{2}$ Ebisawa, 2006.

${ }^{3}$ Ebisawa and Ozawa, 2009.

${ }^{4}$ Kulmiye et. al., 2002.

Saipan Lagoon (Fig. 5). There was a distinct difference in the length classes targeted by the ICS and NUE fishermen. The ICS landed mostly smaller thumbprint emperor in the length classes from 12 to $15 \mathrm{~cm} \mathrm{FL}$, and NUE fishermen targeted fish in length classes from 22 to $25 \mathrm{~cm}$ FL. When length-class percentages from the different data sources were overlain, NUE data covered nearly the entire male length distribution derived from DFW sampling, whereas ICS landings consisted primarily of smaller (Fig. 5) females and males. The highest percentages of thumbprint emperor in annual landings corresponded with hook-and-line landings, as estimated from the ICS. In contrast, landings of thumbprint emperor in 2011 from the BSP came from free-dive spearfishing, composing about $0.8 \%$ of the estimated total annual BSP landings. Table 5 provides

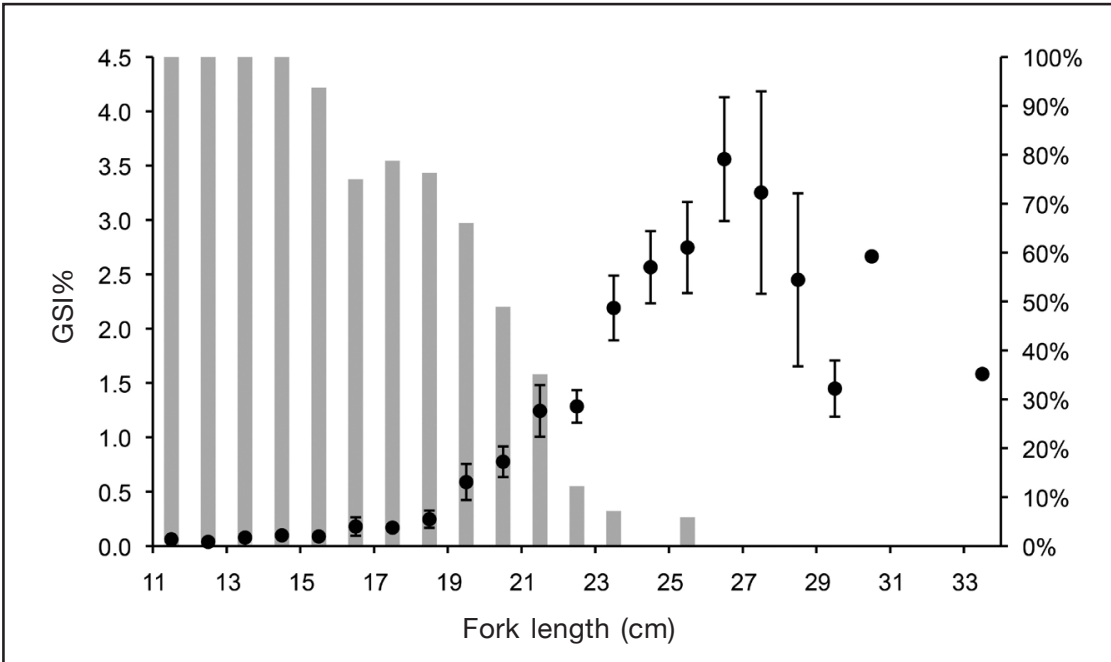

Figure 2

Gonadosomatic index (GSI) values, indicated with black dots, and percentages of individuals that were immature at a given fork length $(\mathrm{cm})$, indicated by gray bars, for thumbprint emperor (Lethrinus harak) collected from Saipan Lagoon during 2005-2006. Error bars on the black dots indicate standard errors of the mean. 


\section{Table 4}

Age and growth parameters, with standard errors of the mean (SEs), for thumbprint emperor (Lethrinus harak), as estimated for Saipan Lagoon with models that used the von Bertalanffy growth function: asymptotic length $\left(L_{\infty}\right)$, Brody growth coefficient $(k)$, the theoretical age at which length is equal to $0\left(t_{0}\right)$, and maximum age estimated $\left(t_{\max }\right)$. The combined, constrained model was constrained to an estimated length at settlement of $15.8 \mathrm{~mm}$ in fork length. All values of $L_{\infty}$ are fork lengths given in centimeters. CI=confidence interval. $n=$ sample size.

\begin{tabular}{lccccc}
\hline Estimated categories & $n$ & $L_{\infty}(\mathrm{SE})$ & $k(\mathrm{SE})$ & $t_{0}$ & $t_{\max }$ \\
\hline Male & 127 & $27.3(1.6)$ & $0.377(0.035)$ & -1.11 & 9 \\
Female & 369 & $37.2(5.7)$ & $0.139(0.049)$ & -2.92 & 9 \\
Combined & 522 & $30.1(1.4)$ & $0.259(0.041)$ & -1.65 & 9 \\
Combined CIs & & $27.2-32.9$ & $0.180-0.340$ & & 9 \\
Combined constrained & 522 & $24.5(0.288)$ & $0.688(0.024)$ & & \\
& & & &
\end{tabular}
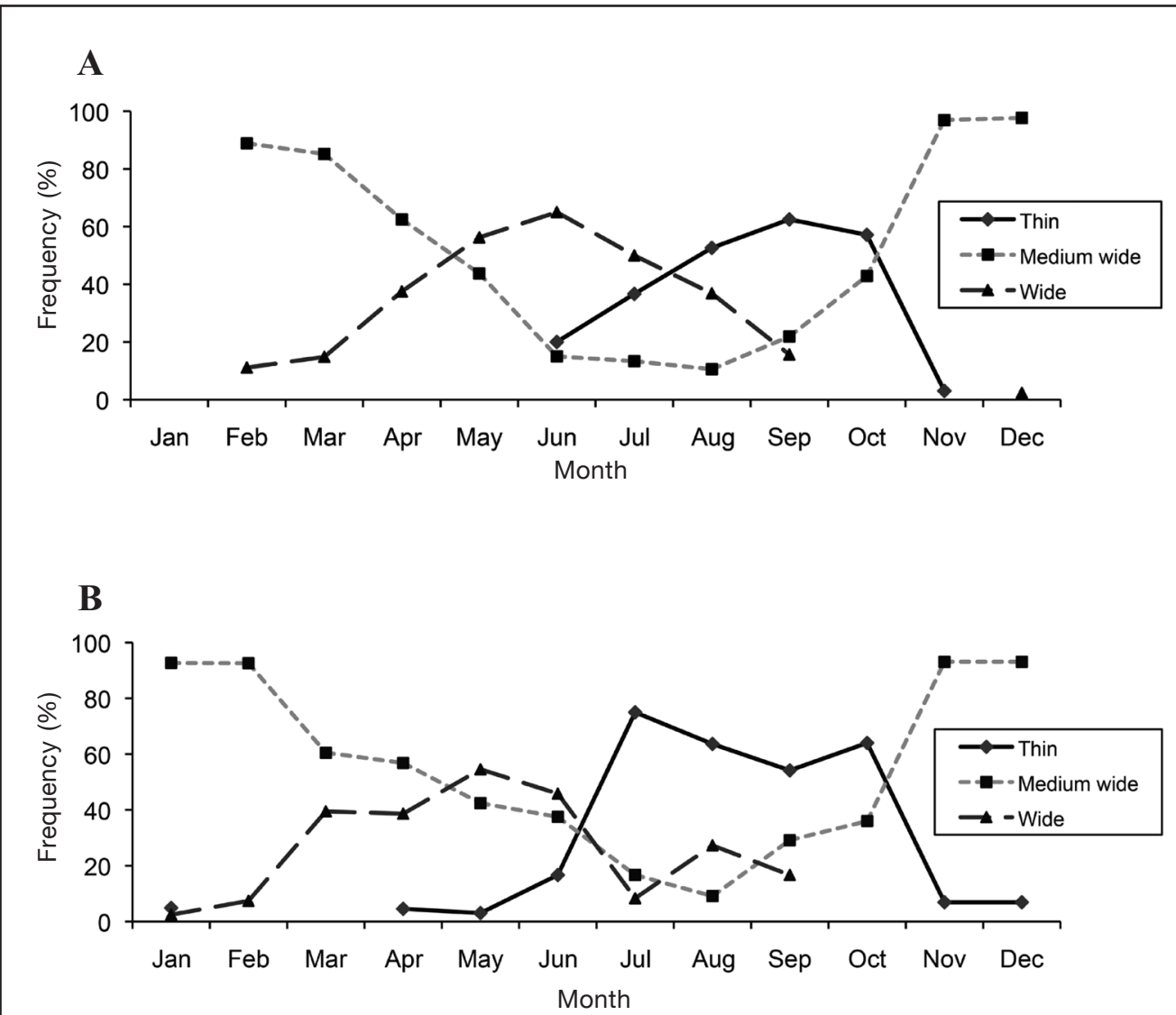

Figure 3

Monthly classification of otolith margins in thumbprint emperor (Lethrinus harak) collected from Saipan Lagoon during (A) $2005(n=281)$ and (B) $2006(n=337)$. The 3 classifications were 1) thin, opaque material visible but not necessarily continuous around otolith margin, 2) medium wide, continuous increment of translucent material visible on the outermost margin of the opaque increment that was less than two-thirds complete; and 3) wide, marginal translucent increment more than two-thirds complete. 

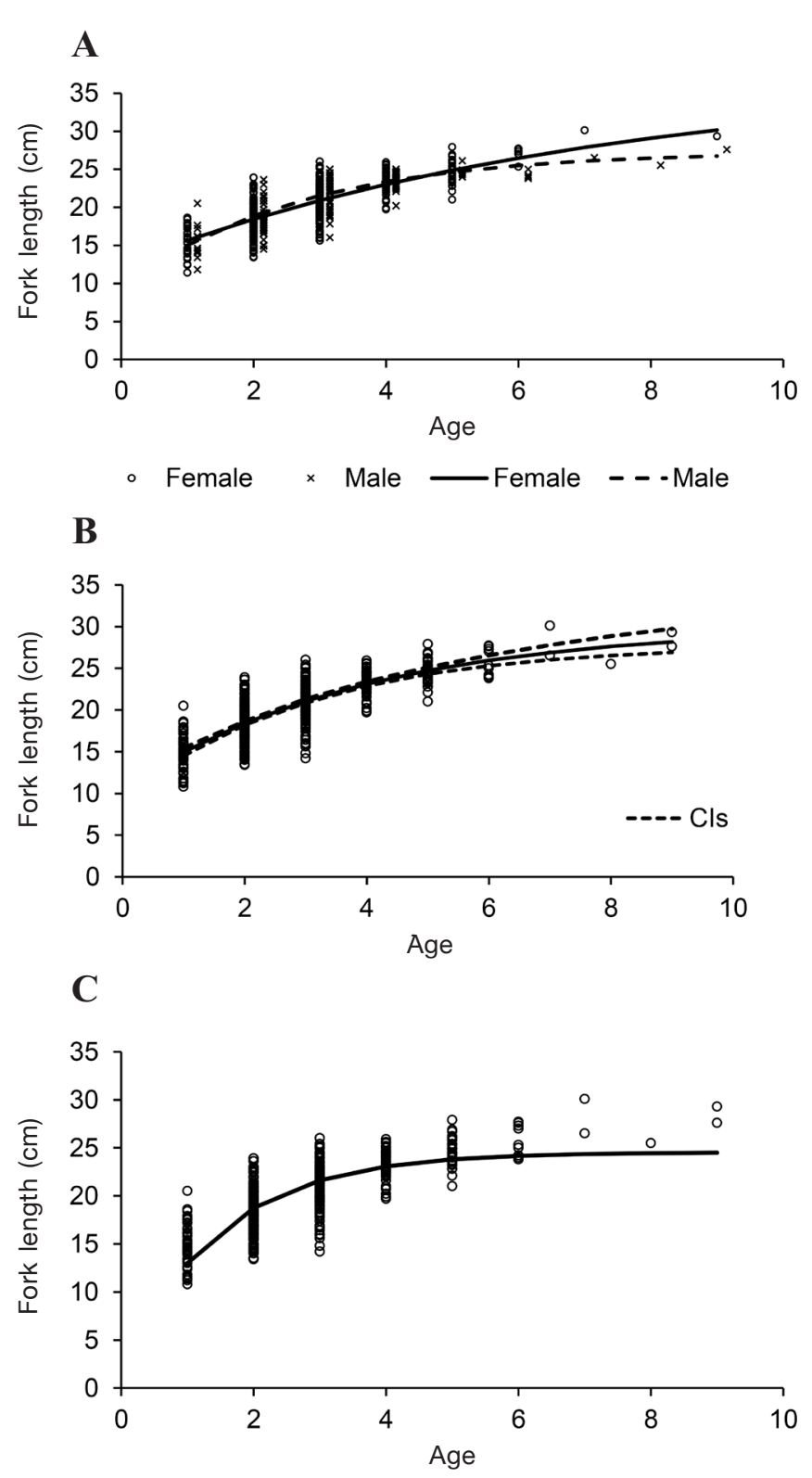

Figure 4

The von Bertalanffy growth curves fitted to observed fork length over age for thumbprint emperor (Lethrinus harak) collected from Saipan Lagoon during 2005-2006 (A) by sex (females, $n=369$; males, $n=127$ ), (B) by both sexes combined ( $n=522)$ with confidence intervals (CIs), and (C) by both sexes combined and with the model constrained to length at settlement. In, graph A, open circles represent female length at age and $\times$ symbols represent male length at age. In graphs B and $\mathrm{C}$, open circles represent length at age.

\section{Spawning potential ratios}

Approximated baseline values of $F$ for 2005-2011 from the ratio of estimated total annual landings of thumbrint emperor from fishery-dependent data sources over estimated biomass from the 2007 and 2011 fishery-independent surveys are given in Table 5. Estimated SPR values at varying levels of $F$ along with approximated values of $F$ and corresponding estimated SPR values from 2005 through 2011 are listed in Table 6. Estimated SPR values for the period 2005-2011 ranged from 0.91 to 0.98 (Table 6).

\section{Mortality}

Estimates of $Z$ with the CC and CR methods had similar ranges: $0.326-0.867$ and $0.473-0.871$, respectively. The $\mathrm{CR}$ model generally produced higher estimates of $Z$ than those produced with the CC model for any given combination of source data, age-length key, and year (Table 7). The estimates of the models were significantly different $(t$-stat=6.57, $\mathrm{df}=17, P<0.00)$. In Figure 6, age frequencies derived from DFW samples, as well as from age-length keys for the period 2005-2006, are overlain with estimated $M$ derived from average length and average weight for the Gislason and Lorenzen estimators. The $M$ estimates from the Gislason model were lower than the estimates derived from the Lorenzen model for all corresponding ages (Fig. 6).

\section{Exploitation rate}

Variability between the 3 estimators of $M$ resulted in a wide range of estimates of exploitation rate (Fig. 7). The $E$ estimates from the use of $M$ from the Lorenzen model were negative in 4 years when $Z$ from the CC method was used and negative for 2 years when $Z$ from the CR method was used (Fig. 7). The $E$ estimates were positive when $Z$ from the CC and CR methods and $M$ from the Gislason et al. (2010) and Hoenig (1983) methods were used. Average values of $E$ from the 3 yearly estimates are depicted as circles in Figure 7. These estimates of $E$ ranged from -0.082 in 2009 (Fig. 7A) to 0.341 in 2011 (Fig. 7B).

Estimates of $M$ from the Gislason model in which VBGF parameter $t_{0}$ was constrained to size at settlement from Japan (15.8 mm FL; Nakamura et al., 2010) produced high estimates of $k$, which led to high estimates of $M$, and no positive $E$ values for estimates derived from $Z$ with the $\mathrm{CC}$ and $\mathrm{CR}$ methods.

\section{Discussion}

Fishing pressure has been found to result in truncated length and age frequencies (Friedlander and DeMar- biomass values from fishery-independent surveys in 2007 and 2011 and the estimated annual landings for the period 2005-2011 that were derived from pooling estimated landings from the ICS, NUE, and CPDS and BSP data. 


\section{Table 5}

Estimated landings (in kilograms) of thumbprint emperor (Lethrinus harak) from Saipan Lagoon for the period 2005-2011 from the Commonwealth of the Northern Mariana Islands Division of Fish and Wildlife inshore creel survey (ICS), commercial reef fish biosampling program (BSP), commercial purchase database system (CPDS), and records of net-use exemptions (NUE), as well as estimated fishing mortality $(F)$ and estimated biomass from fishery-independent surveys (FIS) conducted in 2007 and 2011. Activities covered in the ICS include free-dive spearfishing (Spear) and fishing with hook and line (H\&L) and cast nets. Total landings are given in kilograms and metric tons. The BSP did not begin until 2011.

\begin{tabular}{|c|c|c|c|c|c|c|c|c|c|c|c|c|}
\hline \multirow[b]{2}{*}{ Year } & \multicolumn{5}{|c|}{ ICS } & \multirow[b]{2}{*}{ BSP } & \multirow[b]{2}{*}{ CPDS } & \multirow[b]{2}{*}{ NUE } & \multirow[b]{2}{*}{ Total (kg) } & \multirow[b]{2}{*}{ Total (t) } & \multirow[b]{2}{*}{$F$} & \multirow[b]{2}{*}{ FIS } \\
\hline & Reef fishes & L. harak & Spear & H\&L & Cast net & & & & & & & \\
\hline 2005 & 23,139 & 1310 & 595 & 711 & 4 & - & 648 & 108 & 2066 & 2.06 & 0.050 & $41.5^{2}$ \\
\hline 2006 & 25,360 & 2493 & 680 & 1808 & 5 & - & 940 & 119 & 3552 & 3.55 & 0.085 & $41.5^{2}$ \\
\hline 2007 & 23,349 & 2285 & 536 & 1748 & 1 & - & 665 & 231 & 3181 & 3.18 & 0.085 & $37.5^{1}$ \\
\hline 2008 & 18,523 & 1915 & 197 & 1710 & 9 & - & 623 & 69 & 2607 & 2.61 & 0.063 & $41.5^{2}$ \\
\hline 2009 & 27,201 & 2904 & 236 & 2653 & 15 & - & 535 & 33 & 3472 & 3.47 & 0.084 & $41.5^{2}$ \\
\hline 2010 & 11,267 & 471 & 65 & 405 & 1 & - & 444 & 5 & 920 & 0.92 & 0.022 & $41.5^{2}$ \\
\hline 2011 & 9342 & 477 & 0 & 472 & 5 & 408 & 3 & 64 & 948 & 0.95 & 0.021 & $45.4^{1}$ \\
\hline
\end{tabular}

${ }^{1}$ Estimated biomass from FIS.

${ }^{2}$ Averaged biomass from FIS estimates.

${ }^{3}$ BPS used.

tini, 2002; Graham et al., 2005; Lewin et al., 2006) and in skewed sex ratios of hermaphroditic species (Birkeland and Dayton, 2005; Fenberg and Roy, 2008; Shepherd et al., 2010), and potential effects on stock recruitment (Alonzo and Mangel, 2004; Alonzo et al., 2008) and ecosystem functioning (Zhou et al., 2010; Garcia et al., 2012). The CNMI employs a complete ban on spearfishing with scuba gear, as well as restrictions on the use of gill, drag, and surround nets. Fishermen use nets toward the central parts of Saipan Lagoon in areas dominated by soft sediments, whereas hook-andline fishing occurs mostly from shore near seagrass

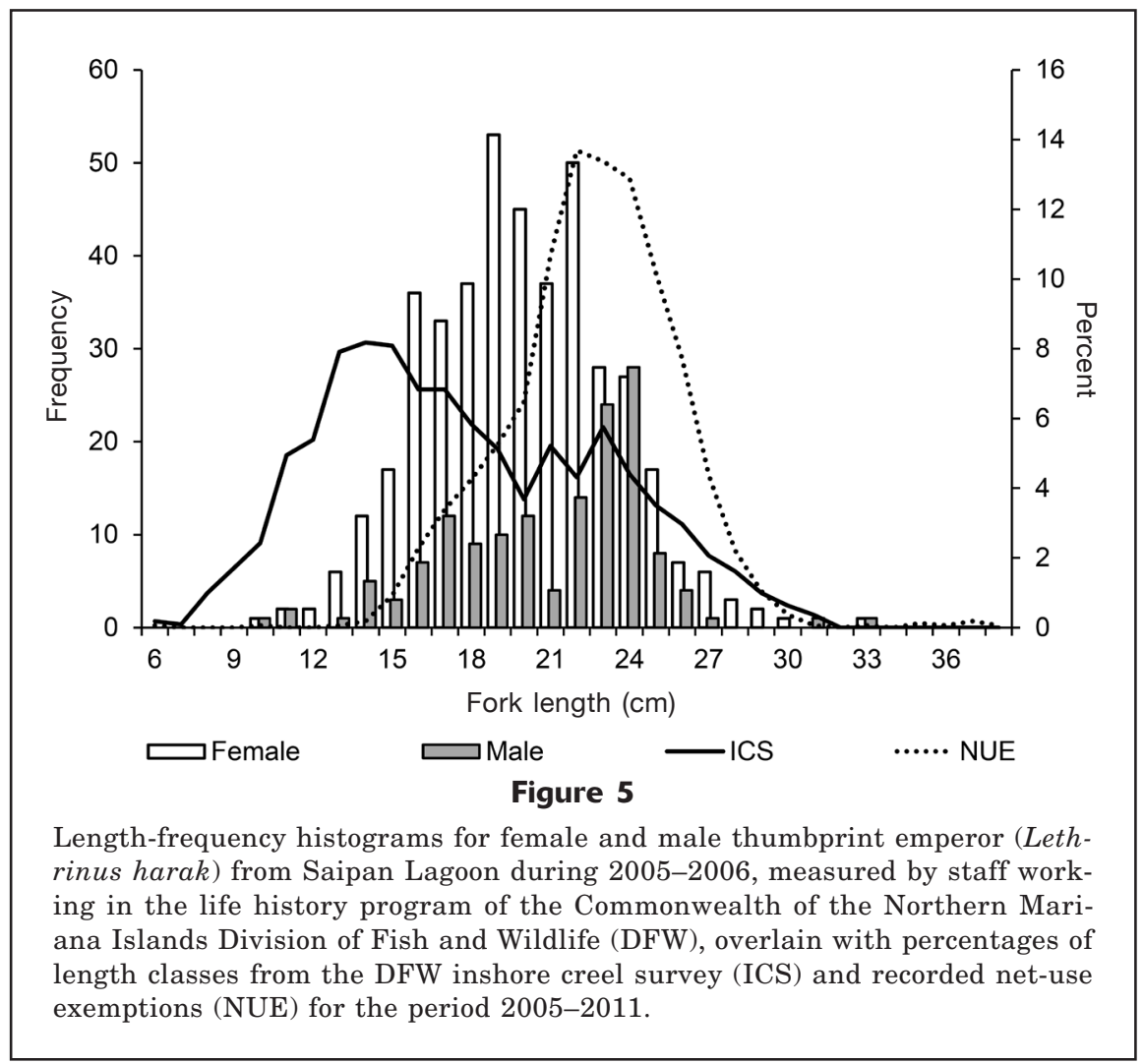




\section{Table 6}

Approximate annual values of fishing mortality $(F)$ and estimated spawning potential ratio (SPR) for thumbprint emperor (Lethrinus harak) collected from Saipan Lagoon during 2005-2011. Values were derived from estimated total landings from fishery-dependent data sources and estimated biomass from fishery-independent survey and were compared with estimated SPRs at differing levels of $F$.

\begin{tabular}{llllll}
\hline \multicolumn{2}{l}{ Estimated from annual landings } & & \multicolumn{2}{c}{ Derived } \\
\cline { 1 - 2 } \cline { 5 - 6 } Year & $F$ & SPR & & $F$ & SPR \\
\hline 2005 & 0.05 & 0.95 & & 0.00 & 1.00 \\
2006 & 0.09 & 0.91 & & 0.25 & 0.78 \\
2007 & 0.08 & 0.91 & & 0.50 & 0.61 \\
2008 & 0.06 & 0.94 & & 0.75 & 0.47 \\
2009 & 0.08 & 0.92 & & 1.00 & 0.37 \\
2010 & 0.02 & 0.98 & & 1.25 & 0.29 \\
2011 & 0.02 & 0.98 & & 1.50 & 0.22 \\
& & & & 1.75 & 0.17 \\
& & & 2.00 & 0.14 \\
& & & & & \\
\end{tabular}

fishing targets smaller (Fig. 5) thumbprint emperors and that fishing pressure on larger thumbprint emperor was probably reduced as a result of regulations on net use.

Length-frequency data in published studies from Kenya (Kulmiye, et al. 2002), Guam (Taylor and McIlwain, 2010), Ryukyu Islands (Ebisawa and Ozawa, 2009), as well as from this study in Saipan Lagoon, show that females were prominent in the largest size classes and, except for females in Saipan Lagoon, were the largest recorded individuals (Table 2). Kulmiye et al. (2002) concluded that identification of hermaphroditism in thumbprint emperor would require further study, but Ebisawa (2006) considered the thumbprint emperor a protogynous hermaphrodite. Sadovy de Mitcheson and Liu (2008) did not designate the thumbprint emperor as a protogynous hermaphrodite, and, although the seemingly complex sexuality of this species may require further inquiry, data from Guam provide evidence for protogyny in that population (Taylor and McIlwain, 2010). Ebisawa (2006) stated that the observed difference in beds, which have been shown to be a preferred habitat for juvenile thumbprint emperor in southern Japan (Nakamura et al., 2009). The difference in length frequencies derived from the Saipan Lagoon ICS and in those derived from NUE data indicate that shoreline sex ratio in the largest size classes in the Ryukyu Islands, where females outnumbered males, was a result of females attaining a larger maximum size than that of males, although Ebisawa and Ozawa (2009) did not distinguish $L_{\infty}$ between the sexes in their study. The

\section{Table 7}

Estimates of total instantaneous mortality $(Z)$ and standard errors of the mean (SEs) from analysis with the linearized catch-curve (CC) method and the Chapman-Robson (CR) method for thumbprint emperor (Lethrinus harak) from Saipan Lagoon. Values are listed by fishery source; inshore creel survey (ICS) or net-use exemption (NUE), year of age-length key (2005-2006), and year of data collection (2005-2011)

\begin{tabular}{lcccccc}
\hline Source & $\begin{array}{c}\text { Year of age- } \\
\text { length key }\end{array}$ & $\begin{array}{c}\text { Year of data } \\
\text { collection }\end{array}$ & $Z(\mathrm{CC})$ & $\mathrm{SE}$ & $Z(\mathrm{CR})$ & $\mathrm{SE}$ \\
\hline $\mathrm{ICS}$ & 2005 & 2006 & 0.549 & 0.051 & 0.598 & 0.036 \\
$\mathrm{ICS}$ & 2005 & 2007 & 0.454 & 0.110 & 0.509 & 0.041 \\
$\mathrm{ICS}$ & 2005 & 2008 & 0.521 & 0.056 & 0.573 & 0.037 \\
$\mathrm{ICS}$ & 2005 & 2009 & 0.326 & 0.046 & 0.473 & 0.033 \\
$\mathrm{ICS}$ & 2006 & 2006 & 0.725 & 0.071 & 0.845 & 0.064 \\
ICS & 2006 & 2007 & 0.674 & 0.094 & 0.760 & 0.072 \\
ICS & 2006 & 2008 & 0.720 & 0.074 & 0.806 & 0.064 \\
ICS & 2006 & 2009 & 0.544 & 0.127 & 0.626 & 0.051 \\
NUE & 2005 & 2005 & 0.431 & 0.150 & 0.664 & 0.036 \\
NUE & 2005 & 2006 & 0.575 & 0.101 & 0.753 & 0.040 \\
NUE & 2005 & 2007 & 0.389 & 0.083 & 0.663 & 0.047 \\
NUE & 2005 & 2009 & 0.368 & 0.127 & 0.639 & 0.790 \\
NUE & 2005 & 2011 & 0.446 & 0.086 & 0.691 & 0.049 \\
NUE & 2006 & 2006 & 0.867 & 0.120 & 0.871 & 0.046 \\
NUE & 2006 & 2007 & 0.659 & 0.142 & 0.756 & 0.052 \\
NUE & 2006 & 2009 & 0.415 & 0.069 & 0.671 & 0.084 \\
NUE & 2006 & 2011 & 0.493 & 0.182 & 0.758 & 0.055 \\
& & & & & & \\
\hline
\end{tabular}




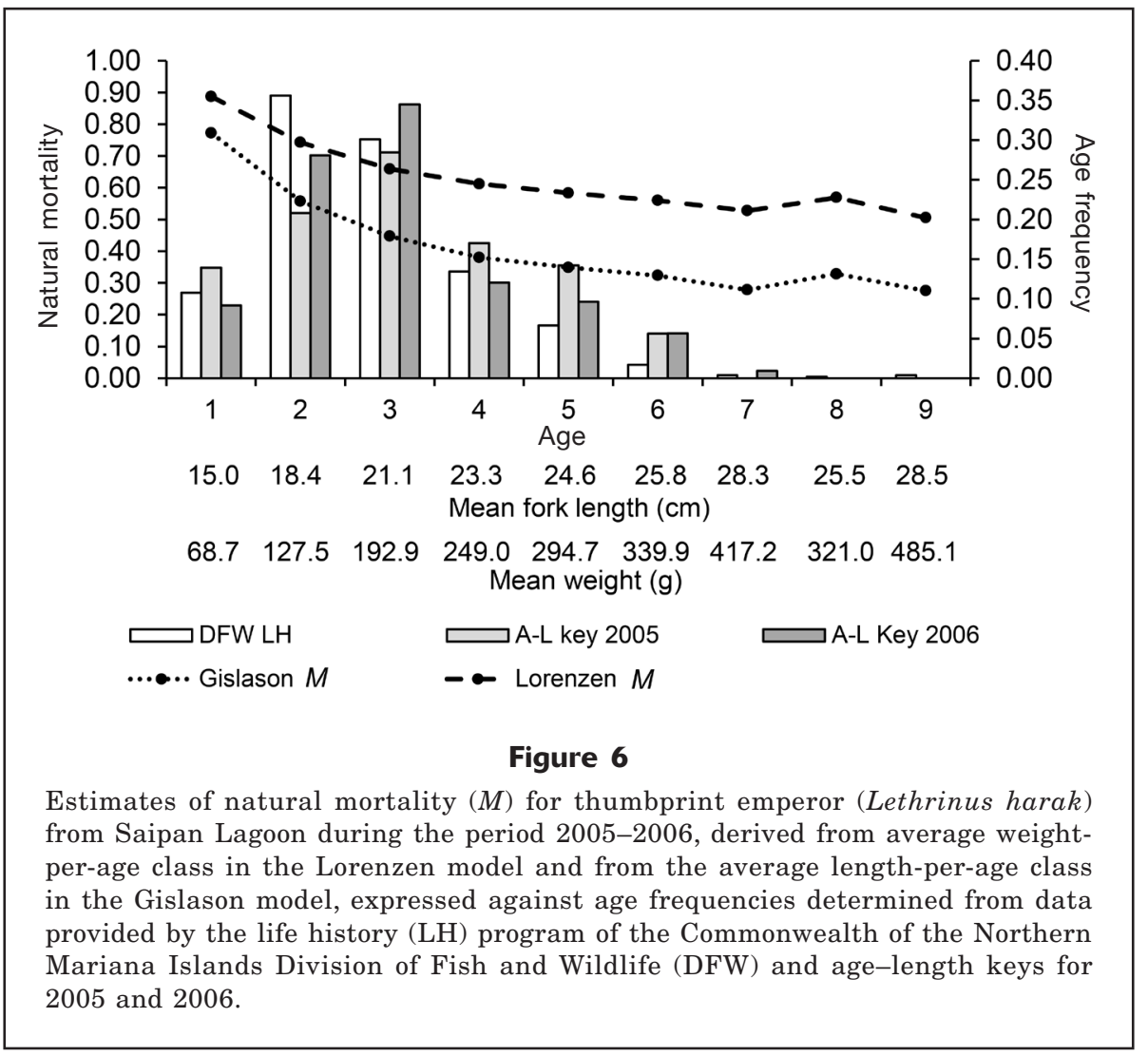

issue of female maximum size in the thumbprint emperor is important given that, in general, larger female fish are exponentially more fecund and potentially more beneficial to population recruitment (Birkeland and Dayton, 2005; Fenberg and Roy, 2008).

The $L_{50}$ value for thumbprint emperor in Saipan Lagoon (19.6 cm FL) was lower than $L_{50}$ values for thumbprint emperor from east Kenya, $23.4 \mathrm{~cm} \mathrm{FL}$ (Kulmiye et al, 2002) and Guam, $20.8 \mathrm{~cm}$ FL (Taylor and McIlwain, 2010). Estimated $L_{50}$ from the Ryuku Islands, $19.5 \mathrm{~cm} \mathrm{FL} \mathrm{(Ebisawa,} \mathrm{2006),} \mathrm{was} \mathrm{similar} \mathrm{to}$ the estimate from this study in Saipan Lagoon. In assessing regional differences in female $A_{50}$, the value of $A_{50}$ for thumbprint emperor in Saipan (2.6 years) was intermediate between the estimate for Guam (Taylor and McIlwain, 2010) and the estimate for the Ryukyu Islands (Ebisawa and Ozawa 2009); see Table 2. Although $L_{\mathrm{T}}$ and $A_{\mathrm{T}}$ were not estimated for thumbprint emperor in Saipan, Taylor and McIlwain (2010) estimated $L_{\mathrm{T}}$ at $24.1 \mathrm{~cm} \mathrm{FL}$ and $A_{\mathrm{T}}$ at 5.38 years for this species in Guam and Ebisawa (2006) estimated $L_{\mathrm{T}}$ at $25.5 \mathrm{~cm}$ FL for thumbprint emperor from the Ryukyu Islands.

Variability in estimates of $L_{50}$ could be introduced by the differing approaches to evaluation of the maturity status of gonads (e.g., gonad histology vs. macroscopic evaluation), by differences in the criteria used to classify maturity status, and by differing analytical approaches to estimation of $L_{50}$ (e.g., graphical [Kul- miye et al., 2002] vs. statistical [Ebisawa, 2006; Taylor and McIlwain, 2010]). In this study of thumbprint emperor in Saipan Lagoon, gonad maturation was evaluated macroscopically and was found to be similar to the macroscopic stages documented by Kulmiye et al. (2002). Taylor and McIlwain (2010) compared macroscopic and microscopic gonad evaluation, and they found that macroscopic staging was adequate $92 \%$ of the time in determining sex of thumbprint emperor and adequate $76 \%$ of the time in determining maturity status. The macroscopic approach provides approximate estimates of $L_{50}$ that need to be calibrated with gonad histological examination to evaluate the accuracy of maturity status classifications, particularly for species that undergo sex change. Such studies would lend support toward the goal of refining macroscopic techniques for use in circumstances in which microscopic staging is not possible, as well as toward the goal of understanding the uncertainties associated with macroscopic staging among families of reef fishes.

Otolith annuli formation in thumbprint emperor from Saipan Lagoon during June through October (Fig. 3 , A and B) was similar to that observed by Ebisawa and Ozawa (2009) in thumbprint emperor from the Ryuku Islands. The similarity in estimates of $L_{50}$ and the timing of otolith annuli formation between thumbprint emperor from Saipan and the Ryukyu Islands seems to indicate some level of demographic correspondence in the western Pacific. However, differences in 

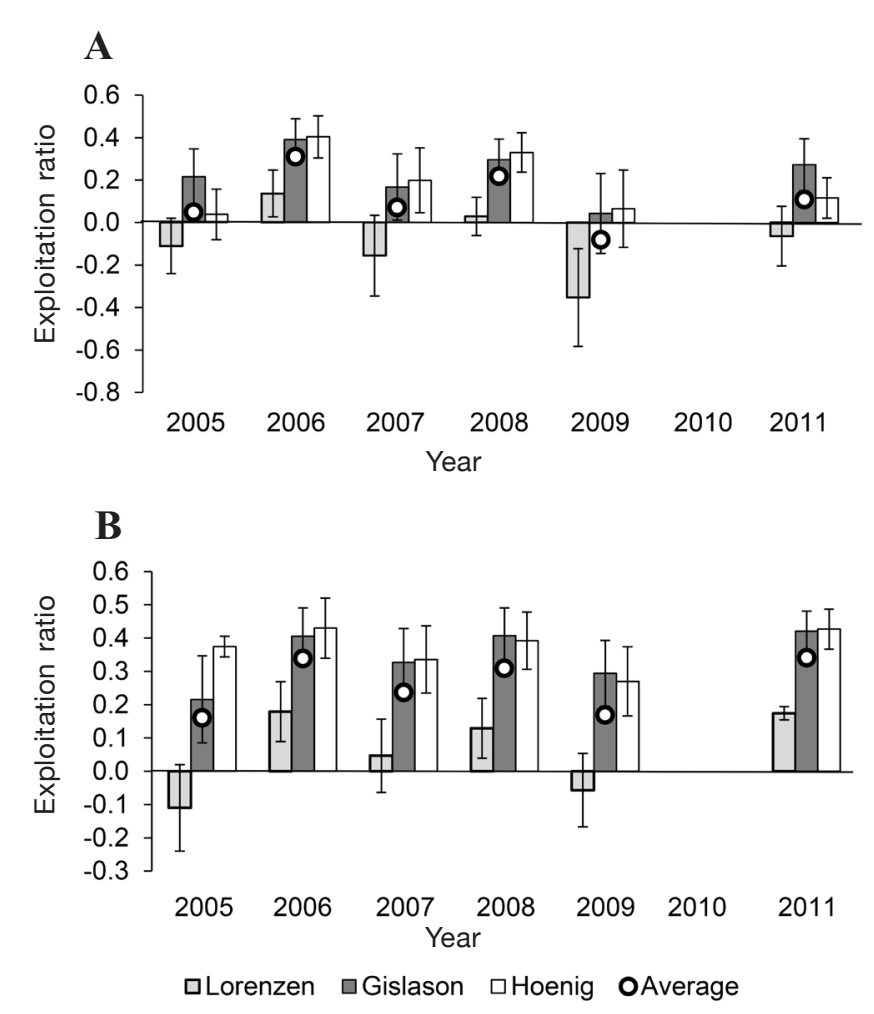

Figure 7

Estimated exploitation ratios for thumbprint emperor ( $L e$ thrinus harak) in Saipan Lagoon for the period 2005-2011, derived from estimates of natural mortality $(M)$ generated from the Lorenzen and Gislason models and from the Hoenig equation, estimates of total mortality based on results from the use of the linearized catch curve and Chapman-Robson methods, and estimates of fishing mortality $(F)$ derived as $F$ $=Z-M$. Exploitation ratios estimated by using total mortality (A) with the linearized catch curve method and (B) with the Chapman-Robson method are shown. The bars depict the means of exploitation estimates, from 1000 simulations, with the use of the stated natural mortality model, and error bars indicate standard deviation. The circles are the averaged values from the listed exploitation rate estimates for that year.

other life history parameters (e.g., $A_{50}$ ) among thumbprint emperor from Saipan, Guam, and the Ryukyu Islands support the need for standardized methods to study reproductive maturity, as well as age and growth for coral reef species. Demographic plasticity for age and growth and in reproductive parameters pertaining to maturity, sex change, or both (Adams et al., 2000; Gust, 2004; Munday et al., 2006; Mariani et al., 2013) has been documented in both gonochoristic (Choat and Robertson, 2002; Robertson et al., 2005) and hermaphroditic (Gust et al., 2002; Donovan et al., 2012) species of coral reef fish.

In addition to altering sex ratios, fishing intensity can alter life history traits, such as length and age at maturity (Heino and Dieckmann, 2008; Sharpe and
Hendry, 2009), the timing of sex transition in hermaphrodites (Hamilton et al., 2007; Götz et al., 2008), size and biomass spectra (Friedlander and DeMartini, 2002; Graham et al., 2005) and, in some cases, coral reef fish community structure through compensatory effects from decreased predation (Dulvy et al., 2004; Ruttenberg et al., 2011). The governments of Guam and Saipan have implemented marine protected areas as means to enhance fishery resources within and outside of those areas, and the CNMI has instituted a ban on spearfishing with scuba gear and has implemented restrictions on the use of gill, drag, and surround nets.

The NUE data for 2005-2011 show that thumbprint emperor composed about $35 \%$ of NUE landings in the CNMI (Tenorio ${ }^{2}$ ), but historical landings of thumbprint emperor in Saipan Lagoon by net fishing were not available for comparison. The commencement of the life history project in Saipan Lagoon shortly after implementation of net-use regulations, coupled with the $22.2 \%$ decline of the Saipan population observed in the CNMI census from 2000 to 2010, suggests that a life history study of thumbprint emperor should be repeated for comparative purposes. Additionally, it would be useful to obtain life history data from an unexploited or lightly exploited population of thumbprint emperor in the CNMI, although acquisition of such data would be logistically challenging within the populated islands of the CNMI where unfished reef flats or embayments are limited. Such a study would provide estimates of $Z$ directly from natural mortality models.

The estimation of $k$ with the VBGF was important in the estimation of $M$ in one of the 3 $M$ models used in this study and, therefore, in the subsequent estimation of $E$. Constraining the VBGF equation to the settlement size for this species produced a high estimate of $k$ and, consequently, a lower estimate of $L_{\infty}$ in comparison with the estimates from the unconstrained equation (Table 4). Constraining the VBGF model to an estimated settlement size resulted in larger estimates of $M$ and in estimates of $E$ that were subsequently negative, indicating that the current levels of fishing mortality were not having a detrimental influence on the thumbprint emperor. In anchoring the fitted VBGF models, in the absence of smaller specimens in the sample, a lack of variability was assumed in the length-age relationship below the smallest fish aged. As shown in this study, constriction had the effect of altering the curve from the fitted VBGF model. Obtaining samples from individuals after settlement, as well

\footnotetext{
2 Tenorio, M. 2012. Personal commun. Division of Fish and Wildlife, Department of Land and Natural Resources, Commonwealth of the Northern Mariana Islands, Saipan, MP 96950.
} 
as more samples from fish in larger size classes to enable more accurate estimation of variability of length at age for these population segments, should remain a goal of life history research, although obtaining fish of those sizes remains a challenging task.

The ratio of estimated annual landings to fisheryindependent biomass estimates from 2005 through 2011 resulted in low values of $\mathrm{F}$ and subsequently to high estimates of SPR. Also, these estimates of $F$ form what can be considered a "rough" baseline, and the high SPR values tend to reflect the nature of fishing for this species. The thumbprint emperor was (and is) not a primary target of the nighttime commercial freedive spear fishery in Saipan, and this species appeared to be primarily harvested by hook and line. Data presented here indicate that larger thumbprint emperors were harvested during fishing activities under net-use exemption-activities that were employed frequently in the past and that have declined since implementation of net-use regulations. One of the purposes of the Magnuson-Stevens Fishery Conservation and Management Act is to achieve and maintain the optimum yield from each fishery through the implementation of fishery management plans, in which the optimum yield is prescribed under certain circumstances on the basis of maximum sustainable yield (MSY). Because MSY is often difficult to estimate for data-moderate and datapoor fisheries, U.S. Fishery Management Councils have used SPR as a proxy for MSY-based precautionary control rules (Restrepo et al., 1998). The exploration of new approaches in the use of SPR for evaluating the status of data-poor fisheries has begun (Hordyk et al., 2015).

Estimates of $E$ were variable because they were derived by sampling within the range of annually derived estimates of $Z$ from 2 common estimation methods (Table 7): by resampling within the $M$ model parameter uncertainty, and through the use of derived $F$ estimates. Results indicate that thumbprint emperor from Saipan Lagoon, with estimated values of average annual E falling below 0.4, were likely not fully exploited. Still, the use of the more conservative value of 0.2 for $E$, as suggested by Pauly (1984), for small fish at lower trophic levels with high recruitment variability, would have resulted in values above 0.2 for 4 of the 6 estimates of $E$ determined with the CR method to estimate $Z$.

In simulations where the CR method and a variety of approaches to $\mathrm{CC}$ analysis were evaluated in the presence of stochastic error, Dunn et al. (2002) found that the CR estimator generally was more precise in estimating true $Z$ values, although any advantage of the $\mathrm{CR}$ method over the CC method decreased with increasing $Z$ estimates and stochastic error. The values of $Z$ generated in this study with the CR model were greater than those derived with the the CC approach, and those higher values of $Z$ resulted in larger estimates of $F$ and subsequently higher estimates of $E$. The use of 3 equations for $M$ and 2 approaches for $Z$ resulted in a range of $E$ values, with uncertainty, for any given year as opposed to the singular values generally produced when $E$ is estimated. All $M$ models come with caveats (Kenchington, 2014), and modifications and improvements in $M$ estimation continue (Gislason et al., 2010). The use of a few $M$ models that resulted in a range of $E$ estimates provides ample uncertainty that may be useful in ascertaining a relative understanding of species status, given a data-poor scenario as described here.

One aspect of the results of this study that should be highlighted is the use of size limits as a fish mortality control for protogynous species in coral reef fisheries. As noted, larger thumbprint emperor are captured in nets than those captured with the fishing methods used in the ICS. If a size limit for thumbprint emperor coincident with $L_{50}$ (e.g., $20 \mathrm{~cm}$ FL) is implemented, about $65 \%$ of the fish landed in the ICS and $17 \%$ of the fish landed as NUE would be prohibited from harvest. Conversely, more than 58\% of males and more than $43 \%$ of females would be harvested, including those females with the greatest fecundity and greatest importance to population recruitment.

Additionally, with respect to estimated ages, lengths, and weights of thumbprint emperor, size limitations would force increased fishing mortality on older and larger size classes of females that have lower estimated rates of $M$ and greater reproductive potential and would eliminate fishing mortality on classes with the highest rates of $M$ and, therefore, the best ability to absorb fishing mortality in the population. Heppell et al. (2006) concluded that catch and effort controls with spatial closures should be enacted to enhance the sustainability of hermaphroditic species, and Fenberg and Roy (2008) noted the potential negative biological effects of size-selective harvesting. The existence of a large marine protected area in Saipan Lagoon, the MMCA, and restrictions on the use of nets appear to be beneficial for thumbprint emperor and may be for other coral reef fish species in Saipan Lagoon.

Standardized methods for estimating life history parameters should be implemented for the macroscopic staging of gonads and be calibrated against histological staging (Brown-Peterson et al., 2011) because dervied life history parameters directly influence estimates of $L_{50}$ and $L_{\mathrm{T}}$, as well as age estimation from sectioned otoliths (Marriott et al., 2010). A standardized approach for estimation of life history parameters will make jurisdictional and regional comparisons practical. In the case of thumbprint emperor from Saipan Lagoon, deficiencies in sample sizes existed for individuals less than 1 year old and for those fish beyond age 6 , in comparison with other age classes. The recent implementation of a BSP, as well as similar programs in other U.S. jurisdictions of the central and western Pacific, provides a useful platform for representative sampling of the fisheries and for the standardization of life history parameters.

The thumbprint emperor in Saipan Lagoon, unlike many other coral reef species in the CNMI, is a data-poor species for which relatively considerable data 
were available or estimable from a number of sources. More species-specific or species-complex data will be required before formal stock assessments can be engaged for coral reef fishes in the CNMI.

\section{Acknowledgments}

Data collection efforts were funded by the Wildlife and Sport Fish Restoration Program of the U.S. Fish and Wildlife Service. Saipan-based Micronesian Environmental Services provided vendor logs for estimations of nonsampled and sampled landings. The Western Pacific Fishery Information Network of the NOAA Pacific Islands Fisheries Science Center (PIFSC) provided data from the DFW's inshore creel survey program and commercial purchase database system. Various personnel from the DFW participated in field and laboratory worked for this project. A preliminary draft was reviewed by R. Humphreys and J. O'Malley of PIFSC. An earlier version of the manuscript benefited substantially from the comments of 3 reviewers.

\section{Literature cited}

Adams, S., B. D. Mapstone, G. R. Russ, and C. R. Davies. 2000. Geographic variation in the sex ratio, sex specific size, and age structure of Plectropomus leopardus (Serranidae) between reefs open and closed to fishing on the Great Barrier Reef. Can. J. Fish. Aquat. Sci. 57:1448-1458. Article

Alonzo, S. H., and M. Mangel.

2004. The effects of size selective fisheries on the stock dynamics of and sperm limitation in sex changing fish. Fish. Bull. 102:1-13.

Alonzo, S. H., T. Ish, M. Key, A. D. MacCall, and M. Mangel. 2008. The importance of incorporating protogynous sex change into stock assessments. Bull. Mar. Sci. 83:163-179.

Beddington, J. R., and G. P. Kirkwood.

2005. The estimation of potential yield and stock status using life-history parameters. Philos. Trans. R. Soc. B 360:163-170. Article

Beverton, R. J. H., and S. J. Holt.

1957. On the dynamics of exploited fish populations. Fisheries Investigation Series 2, vol. 19, 533 p. Ministry of Agriculture, Fisheries, and Food, London.

Birkeland, C., and P. K. Dayton.

2005 The importance in fishery management of leaving the big ones. Trends Ecol. Evol. 20:356-358. Article

Brown, I. W., and W. D. Sumpton.

1998. Age, growth and mortality of redthroat emperor Lethrinus miniatus (Pisces: Lethrinidae) from the southern Great Barrier Reef, Queensland, Australia. Bull. Mar. Sci. 62:905-917.

Brown-Peterson, N. J., D. M. Wyanski, F. Saborido-Rey, B. J. Macewicz, and S. K. Lowerre-Barbieri.

2011. A standardized terminology for describing reproductive development in fishes. Mar. Coast. Fish. 3:52-70. Article

Carpenter, K. E.

2001. Lethrinidae: Emperor (emperor snappers). In The living marine resources of the Western Central Pacific, vol. 5. Bony fishes, part 3 (Menidae to Pomacentridae) (K. E. Carpenter and V. H. Niem, eds.), p. 3004-3050. FAO, Rome.

Chapman, D. G., and D. S. Robson.

1960. The analysis of a catch curve. Biometrics 16:354-368

Chen, Y., D. A. Jackson, and H. H. Harvey.

1992. A comparison of von Bertalanffy and polynomial functions in modelling fish growth data. Can. J. Fish. Aquat. Sci. 49:1228-1235. Article

Choat, J. H., and L. M. Axe.

1996. Growth and longevity in acanthurid fishes; an analysis of otolith increments. Mar. Ecol. Prog. Ser. 134:15-26. Article

Choat, J. H., and D. R. Robertson.

2002. Age-based studies. In Coral reef fishes: dynamics and diversity in a complex ecosystem (P. F. Sale, ed.), p 57-80. Academic Press, New York. Article

Choat, J. H., L. M. Axe, and D. C. Lou.

1996. Growth and longevity in fishes of the family Scaridae. Mar. Ecol. Prog. Ser. 145:33-41. Article

Cochran, W. G.

1977. Sampling techniques, 3rd ed., 428 p. John Wiley \& Sons Inc., New York.

Currey, L. M., A. J. Williams, B. D. Mapstone, C. R. Davies, G. Carlos, D. J. Welch, C. A. Simpfendorfer, A. C. Ballagh, A. L. Penny, E. M Grandcourt, et al.

2013. Comparative biology of tropical Lethrinus species (Lethrinidae): challenges for multi-species management. J. Fish Biol. 82:764-788. Article

Dalzell, P., S. Sharma, and G. Nath.

1992. Estimation of exploitation rates in a multispecies emperor (Pisces: Lethrinidae) fishery in Fiji, based on length frequency data. In Papers on fisheries science from the Pacific Islands, vol. 1 (P. Dalzell, ed.), p. 4350. South Pacific Commission, Noumea, New Caledonia.

Dalzell, P., T. J. H. Adams, and N. V. C. Polunin.

1996. Coastal fisheries in the Pacific Islands. Oceanogr. Mar. Biol., Annu. Rev. 34:395-531.

Dick, E. J., and A. D. MacCall.

2011. Depletion-based stock reduction analysis: a catchbased method for determining sustainable yields for data-poor fish stocks. Fish. Res. 110:331-341. Article

Donovan, M. K., A. M. Friedlander, E. E. DeMartini, M. J. Donahue, and I. D. Williams.

2012. Demographic patterns in the peacock grouper (Cephalopholis argus), an introduced Hawaiian reef fish. Environ. Biol. Fish. 96:981-994. Article

Dulvy, N. K., N. V. Polunin, A.C. Mill, and N. A. Graham. 2004. Size structural change in lightly exploited coral reef fish communities: evidence for weak indirect effects. Can. J. Fish. Aquat. Sci. 61:466-475. Article

Dunn, A R. I. C. C. Francis, and I. J. Doonan.

2002. Comparison of the Chapman-Robson and regression estimators of $Z$ from catch-curve data when non-sampling stochastic error is present. Fish. Res. 59:149-159. Article

Ebisawa, A.

1990. Reproductive biology of Lethrinus nebulosus (Pisces: Lethrinidae) around the Okinawan waters. Nippon Suisan Gakkaishi 56:1941-1954. Article

2006. Reproductive and sexual characteristics in five Lethrinus species in waters off the Ryukyu Islands. Ichthyol. Res. 53:269-280. Article 
Ebisawa, A, and T. Ozawa.

2009. Life-history traits of eight Lethrinus species from two local populations in waters off the Ryukyu Islands. Fish. Sci. 75:553-566. Article

Fenberg, P. B., and K. Roy.

2008. Ecological and evolutionary consequences of sizeselective harvesting: how much do we know? Mol. Ecol. 17:209-220. Article

Friedlander, A. M., and E. E. DeMartini.

2002. Contrasts in density, size, and biomass of reef fishes between the northwestern and the main Hawaiian Islands: the effects of fishing down apex predators. Mar. Ecol. Prog. Ser. 230: 253-264. Article

Garcia, S. M., J. Kolding, J. Rice, M. J. Rochet, S. Zhou, T. Arimoto, J. E. Beyer, L. Borges, A. Bundy, D. Dunn, et al.

2012. Reconsidering the consequences of selective fisheries. Science 335:1045-1047. Article

Gislason, H., N. Daan, J. C. Rice, and J. G. Pope.

2010. Size, growth, temperature and the natural mortality of marine fish. Fish Fish. 11:149-158. Article

Goodyear, C. P.

1993. Spawning stock biomass per recruit in fisheries management: foundation and current use. In Risk evaluation and biological reference points for fisheries management (S. J. Smith, J. J. Hunt, and D. Rivard, eds.), p. 67-81. Can. Spec. Pub. Fish. Aquat. Sci. 120.

Götz, A., S. E. Kerwath, C. G. Attwood, and W. H. H. Sauer. 2008. Effects of fishing on population structure and life history of roman Chrysoblephus laticeps (Sparidae). Mar. Ecol. Prog. Ser. 362:245-259. Article

Graham, N. A. J., N. K. Dulvy, S. Jennings, and N. V. C. Polunin.

2005. Size-spectra as indicators of the effects of fishing on coral reef fish assemblages. Coral Reefs 24:118-124. Article

Grandcourt, E. M.

2002. Demographic characteristics of a selection of exploited reef fish from the Seychelles: preliminary study. Mar. Freshw. Res. 53:123-130. Article

Grandcourt, E. M., T. Z. Al Abdessalaam, F. Francis, and A. T. Al Shamsi.

2010. Reproductive biology and implications for management of the spangled emperor Lethrinus nebulosus in the southern Arabian Gulf. J. Fish Biol. 77:2229-2247. Article

Gulland, J. A.

1970. The fish resources of the ocean. FAO Fish. Tech. Pap. 97, 425 p.

Gust, N.

2004. Variation in the population biology of protogynous coral reef fishes over tens of kilometres. Can. J. Fish. Aquat. Sci. 61:205-218. Article

Gust, N., J. Choat, and J. Ackerman.

2002. Demographic plasticity in tropical reef fishes. Mar. Biol. 140:1039-1051. Article

Hamilton, S. L., J. E. Caselle, J. D. Standish, D. M. Schroeder, M. S. Love, J. A. Rosales-Casian, and O. Sosa-Nishizaki.

2007. Size-selective harvesting alters life histories of a temperate sex-changing fish. Ecol. Appl. 17:2268-2280. Article

Heino, M, and U. Dieckmann.

2008. Detecting fisheries-induced life-history evolution: an overview of the reaction-norm approach. Bull. Mar. Sci. 83:69-93.
Heppell, S. S., S. A. Heppell, F. C. Coleman, and C. C. Koenig. 2006. Models to compare management options for a protogynous fish. Ecol. Appl. 16:238-249. Article

Hoenig, J. M.

1983. Empirical use of longevity data to estimate mortality rates. Fish. Bull. 81:898-903.

Hoenig, J. M., and D. M. Heisey.

1987. Use of a log-linear model with the EM algorithm to correct estimates of stock composition and to convert length to age. Trans. Am. Fish. Soc. 116:232-243. Article

Hordyk, A., K. Ono, K. Sainsbury, N. Loneragan, and J. Prince. 2015. Some explorations of the life history ratios to describe length composition, spawning-per-recruit, and the spawning potential ratio. ICES J. Mar. Sci. 72:204-216. Article

Jiao, Y, E. Cortés, K. Andrews, and F. Guo.

2011. Poor-data and data-poor species stock assessment using a Bayesian hierarchical approach. Ecol. Appl. 21:2691-2708. Article

Kenchington, T. J.

2014. Natural mortality estimators for information limited fisheries. Fish Fish. 15:533-562. Article

Kulmiye, A. J., M. J. Ntiba, and S. M. Kisia.

2002. Some aspects of the reproductive biology of the thumbprint emperor, Lethrinus harak (Forsskål, 1775), in Kenyan coastal waters. West. Indian Ocean J. Mar. Sci. 1:135-144.

Laursen, T., G. R. Russ, S. J. Newman, and J. B. Higgs.

1999. Age, growth and mortality of Gymnocranius audleyi (Pisces: Lethrinidae). Asian Fish. Sci. 12:187-200.

Lewin, W. C., R. Arlinghaus, and T. Mehner.

2006. Documented and potential biological impacts of recreational fishing: insights for management and conservation. Rev. Fish. Sci. 14:305-367. Article

Lo Galbo, A. M., K. E. Carpenter, and D. L. Reed.

2002. Evolution of trophic types in emperor fishes (Lethrinus, Lethrinidae, Percoidei) based on cytochrome b gene sequence variation. J. Mol. Evol. 54:754-762. Article

Lorenzen, $\mathrm{K}$.

1996. The relationship between body weight and natural mortality in juvenile and adult fish: a comparison of natural ecosystems and aquaculture. J. Fish Biol. 49:627-647. Article

MacCall, A. D.

2009. Depletion-corrected average catch: a simple formula for estimating sustainable yields in data-poor situations. ICES J. Mar. Sci. 66:2267-2271. Article

Mariani, S., M. Sala-Bozano, J. Chopelet, and C. Benvenuto.

2013. Spatial and temporal patterns of size-at-sex-change in two exploited coastal fish. Environ. Biol. Fish. 96:535-541. Article

Marriott, R. J., B. D. Mapstone, A. C. Ballagh, L. M. Currey, A. Penny, A. J. Williams, G. Jackson, D. Lou, A. J. Mapleston, N. D. C. Jarvis, et al.

2010. Accepting final counts from repeat readings of otoliths: should a common criterion apply to the age estimation of fish? Mar. Freshw. Res. 61:1171-1184. Article

McGilliard, C. R., R. Hilborn, A. MacCall, A. E. Punt, and J. C. Field.

2011. Can information from marine protected areas be used to inform control-rule-based management of smallscale, data-poor stocks? ICES J. Mar. Sci, 68:201-211. Article 
Munday, P. L., P. M. Buston, and R. R. Warner. 2006. Diversity and flexibility of sex-change strategies in animals. Trends Ecol. Evol. 21:89-95. Article

Myers, R. F.

1999. Micronesian reef fishes: a comprehensive guide to the coral reef fishes of Micronesia, $3^{\text {rd }}$ ed., $330 \mathrm{p}$. Coral Graphics, Barrigada, Guam.

Nakamura, Y., M. Horinouchi, M. Sano, and T. Shibuno. 2009. The effects of distance from coral reefs on seagrass nursery use by 5 emperor fishes at the southern Ryukyu Islands, Japan. Fish. Sci. 75:1401-1408. Article

Nakamura, Y., T. Shibuno, N. Suzuki, J. Nakamori, K. Kanashiro, and Y. Watanabe.

2010. Interspecific variations in age and size at settlement of 8 emperor fishes (Lethrinidae) at the southern Ryukyu Islands, Japan. Fish. Sci. 76:503-510. Article

Nanami, A., and H. Yamada.

2009. Site fidelity, size, and spatial arrangement of daytime home range of thumbprint emperor Lethrinus harak (Lethrinidae). Fish. Sci. 75:1109-1116. Article

Pauly, D.

1984. Fish population dynamics in tropical waters: a manual for use with programmable calculators. ICLARM Stud. Rev. 8, 325 p. International Center for Living Aquatic Resources Management, Manila, Philippines.

Punt, A. E., D. C. Smith, and A. D. M. Smith.

2011. Among-stock comparisons for improving stock assessments of data-poor stocks: the "Robin Hood" approach. ICES J. Mar. Sci: 68:972-981. Article

$\mathrm{R}$ Core Team.

2015. R: a language and environment for statistical computing. R Foundation for Statistical Computing, Vienna, Austria. [Available at website, accessed May 2015.]

Restrepo, V. R., G. G. Thompson, P. M. Mace, W. L. Gabriel, L. L. Low, A. D. MacCall, R. D. Methot, J. E. Powers, B. L. Taylor, P. R. Wade, et al.

1998. Technical guidance on the use of precautionary approaches to implementing National Standard 1 of the Magnuson-Stevens Fishery Conservation and Management Act. NOAA Tech. Memo, NMFS-F/SPO-31, 48 p.

Robertson, D. R., J. L. Ackerman, J. H. Choat, J. M. Posada, and J. Pitt.

2005. Ocean surgeonfish Acathurus bahianus. I. The geography of demography. Mar. Ecol. Prog. Ser. 295:229244. Article

Robson, D. S., and D. G. Chapman.

1961. Catch curves and mortality rates. Trans. Am. Fish. Soc. 90:181-189. Article
Ruttenberg, B. I., S. L. Hamilton, S. M. Walsh, M. K. Donovan, A. Friedlander, E. E. DeMartini, E. Sala, and S. A. Sandin.

2011. Predator-induced demographic shifts in coral reef fish assemblages. PLoS ONE 6(6):e21062. Article

Sadovy de Mitcheson, Y., and M. Liu.

2008. Functional hermaphroditism in teleosts. Fish Fish. 9:1-43. Article

Sharpe, D. M. T., and A. P. Hendry.

2009. Life history change in commercially exploited fish stocks: an analysis of trends across studies. Evol. Appl. 2:260-275. Article

Shepherd, S. A., J. B. Brook, and Y. Xiao.

2010. Environmental and fishing effects on the abundance, size and sex ratio of the blue throated wrasse, Notolabrus tetricus, on South Australian coastal reefs. Fish. Manage. Ecol. 17:209-220. Article

Shibuno, T., Y. Nakamura, M. Horinouchi, and M. Sano.

2008. Habitat use patterns of fishes across the mangroveseagrass-coral reef seascape at Ishigaki Island, southern Japan. Ichthyol. Res. 55:218-237. Article

Sumpton, W., and I. Brown.

2004. Reproductive biology of the red throat emperor Lethrinus miniatus (Pisces: Lethrinidae) from the southern Great Barrier Reef, Australia. Bull. Mar. Sci. 74:423-432

Taylor, B. M., and J. L. McIlwain.

2010. Beyond abundance and biomass: effects of marine protected areas on the demography of a highly exploited reef fish. Mar. Ecol. Prog. Ser. 411: 243-258. Article

Trianni, M. S.

2011. Biological characteristics of the spotcheek emperor, Lethrinus rubrioperculatus, in the Northern Mariana Islands. Pac. Sci. 65:345-363. Article

von Bertalanffy, L.

1938. A quantitative theory of organic growth (inquiries on growth laws. II). Hum. Biol. 10:181-213.

Williams, A. J., C. R. Davies, B. D. Mapstone, and G. R. Russ. 2003. Scales of spatial variation in demography of a large coral reef fish-an exception to the typical model? Fish. Bull. 101:673-683.

Williams, A. J., B. D. Mapstone, and C. R. Davies.

2007. Spatial and interannual patterns in growth of an exploited coral-reef fish. J. Fish Biol. 71:970-992. Article

Zhou, S., A. D. M Smith, A. E. Punt, A. J. Richardson, M. Gibbs, E. A. Fulton, S. Pascoe, C. Bulman, P. Bayliss, and K. Sainsbury.

2010. Ecosystem-based fisheries management requires a change to the selective fishing philosophy. Proc. Natl. Acad. Sci. USA 107: 9485-9489. Article 